\title{
Calcium Current in Cortical Astrocytes: Induction by cAMP and Neurotransmitters and Permissive Effect of Serum Factors
}

\author{
Barbara A. Barres, ${ }^{1,2,3,4}$ Linda L. Y. Chun, ${ }^{1,2}$ and David P. Corey ${ }^{1,2,3}$ \\ 'Program in Neuroscience, Harvard Medical School, 'Department of Neurology, Massachusetts General Hospital, and \\ 3Howard Hughes Medical Institute, Boston, Massachusetts 02114
}

\begin{abstract}
Voltage-dependent L-type calcium channels were induced in highly purified, cultured, cortical astrocytes by exposure to substances known to increase their intracellular cAMP: 8-bromo-cAMP, forskolin, isoproterenol, and vasoactive intestinal peptide. In untreated control cultures, L-type calcium currents were entirely absent. The induction of this calcium current was specific to cortical astrocytes and a closely related astrocyte type in white matter and did not occur in meningeal cells or oligodendrocytes. The ability of forskolin to induce L-type calcium current in astrocytes depended on previous culture of these cells in a permissive lot of serum for at least $48 \mathrm{hr}$. In addition, certain lots of sera caused expression of a voltage-dependent T-type calcium channel in untreated control cultures. Several possible mechanisms of calcium channel induction by CAMP are consistent with our data: modification of a silent channel already present in the membrane, indirect effect of cytoskeletal alteration, or insertion of channels from submembrane stores. If the environment in vivo is permissive, regulation of glial ion channels may be under neuronal control.
\end{abstract}

Although most functions of astrocytes are still poorly understood, one function has been convincingly demonstrated: astrocytes participate in the regulation of ions in the neuronal microenvironment (Coles and Orkand, 1983; Ballanyi et al., 1987). Recently, astrocytes in culture have been demonstrated to express several kinds of voltage-sensitive ion channels that might mediate this function. In particular, cortical astrocytes in culture express sodium channels (Bevan et al., 1985), chloride channels (Bevan et al., 1985), and several types of potassium channels, including a calcium-dependent potassium channel (Quandt and MacVicar, 1986).

There is also some evidence for a calcium channel. Astrocytes in culture fire slow action potentials when bathed in a solution that would accentuate calcium current and inhibit potassium current (MacVicar, 1984). We have used the whole-cell patchclamp recording technique to measure calcium current directly and to characterize its properties. We found that cortical astro-

\footnotetext{
Received Dec. 19, 1988; revised Feb. 16, 1989; accepted Feb. 20, 1989

We thank Michael Goy for his advice and donation of forskolin for the initial experiments, and Bruce Silverstein for expert technical assistance. This work was supported by National Institute of Health grants F32 NS-07970 (to B.A.B.), RO1 NS-22059 (to D.P.C.), and RO1 NS-21269 and RO1 NS-16367 (to L.L.Y.C.) and by the Howard Hughes Medical Institute.

Correspondence should be addressed to Barbara A. Barres, Wellman 414, Massachusetts General Hospital, Boston, MA 02114.

Copyright (C) 1989 Society for Neuroscience 0270-6474/89/093169-07\$02.00/0
}

cytes did not express a voltage-dependent calcium current in control cultures but that an L-type calcium current was induced by preincubation with agents that raise intracellular cAMP. Furthermore, isoproterenol and vasoactive intestinal peptide (VIP), which raise cAMP levels in cortical astrocytes (McCarthy and de Vellis, 1978; Narumi et al., 1978; Rougon et al., 1983), also induced this calcium current. A preliminary report of this work has appeared in abstract form (Chun et al., 1986).

\section{Materials and Methods}

Preparation of cortical cell suspensions. Cerebral cortices from postnatal day-1 Long/Evans rats were stripped of their meninges and dissociated enzymatically to make a suspension of single cells, essentially as described by Huettner and Baughman (1986). Briefly, the tissue was minced and incubated at $37^{\circ} \mathrm{C}$. for $75 \mathrm{~min}$ in a papain solution $(30 \mathrm{units} / \mathrm{ml}$; Worthington) equilibrated with $95 \% \mathrm{O}_{2}$ and $5 \% \mathrm{CO}_{2}$. This solution also contained Earle's balanced salts, calcium, magnesium, EDTA, sodium bicarbonate, glucose, and L-cysteine. The tissue was then triturated with a $1 \mathrm{ml}$ pipette in a solution containing ovomucoid $(0.2 \%$, BoehringerMannheim) and BSA ( $0.1 \%$; Sigma) to yield a suspension of single cells.

Preparation of cortical astrocyte cultures. Cultures of cerebral cortical astrocytes were prepared from postnatal day 1 rat cell suspensions (as above) with the technique of McCarthy and deVellis (1980) and further puritied by the procedure of Noble and Murray (1984). Primary cultures of astrocytes were plated at 20 million cells per $75 \mathrm{~cm}^{2}$ flask and grown to confluence in a medium containing Dulbecco's modified Eagle's medium, $10 \%$ fetal calf serum, penicillin (100 units $/ \mathrm{ml})$, streptomycin $(100$ $\mu \mathrm{g} / \mathrm{ml}$ ), and L-glutamine ( $2 \mathrm{~mm}$ ). The top layer of cells, containing oligodendrocytes, type 2 astrocytes and progenitor cells, was shaken off manually, and the remaining cells were treated with cytosine arabinoside $(25 \mu \mathrm{M})$ for 2 days to kill dividing cells. Finally, these cells were trypsinized from the flask, and most contaminating cells were destroyed by complement-dependent lysis using monoclonal antibodies directed at galactocerebroside (GC; antibodies were generously provided by Barbara Ranscht; Ranscht et al., 1982) and the A2B5 antigen (Eisenbarth et al., 1979; the A2B5 cell line was obtained from American Type Culture Collection). These recognize surface antigens on oligodendrocytes and on type 2 astrocytes and neurons, respectively (Raff et al., 1983b). The cells were then plated on 13-mm-diameter round coverslips coated with poly-l-lysine. The final cultures were demonstrated to be greater than $98 \%$ pure astrocytes, based on immunohistochemical labeling with markers to glial fibrillary acidic protein (GFAP), A2B5, and GC. The cultures were at least 1 month old before recording.

Electrophysiological recording. Tight-seal, whole-cell patch recording. A piece of glass coverslip bearing cultural cortical astrocytes was placed in the recording chamber, which contained an appropriate bath solution (volume 500-750 $\mathrm{\mu l}$ ). Standard procedures for pipette preparation, seal formation, and whole-cell recording were used (Hamill et al., 1981; Corey et al., 1984). Micropipelles were drawn from hard borosilicate capillary glass (Corning 7052, Garner Glass), coated with Sylgard to reduce their capacitance, and fire-polished to a bubble number of $4.0-$ 4.5 (corresponding to an internal tip diameter of about $0.6-0.8 \mu \mathrm{m}$ ) (Corey and Stevens, 1983). Pipette capacitance and series resistance were electronically compensated by the patch clamp, a Yale Mark V. All experiments were done at room temperature, approximately $23^{\circ} \mathrm{C}$.

Data acquisition and analysis. Voltage stimuli were generated and 

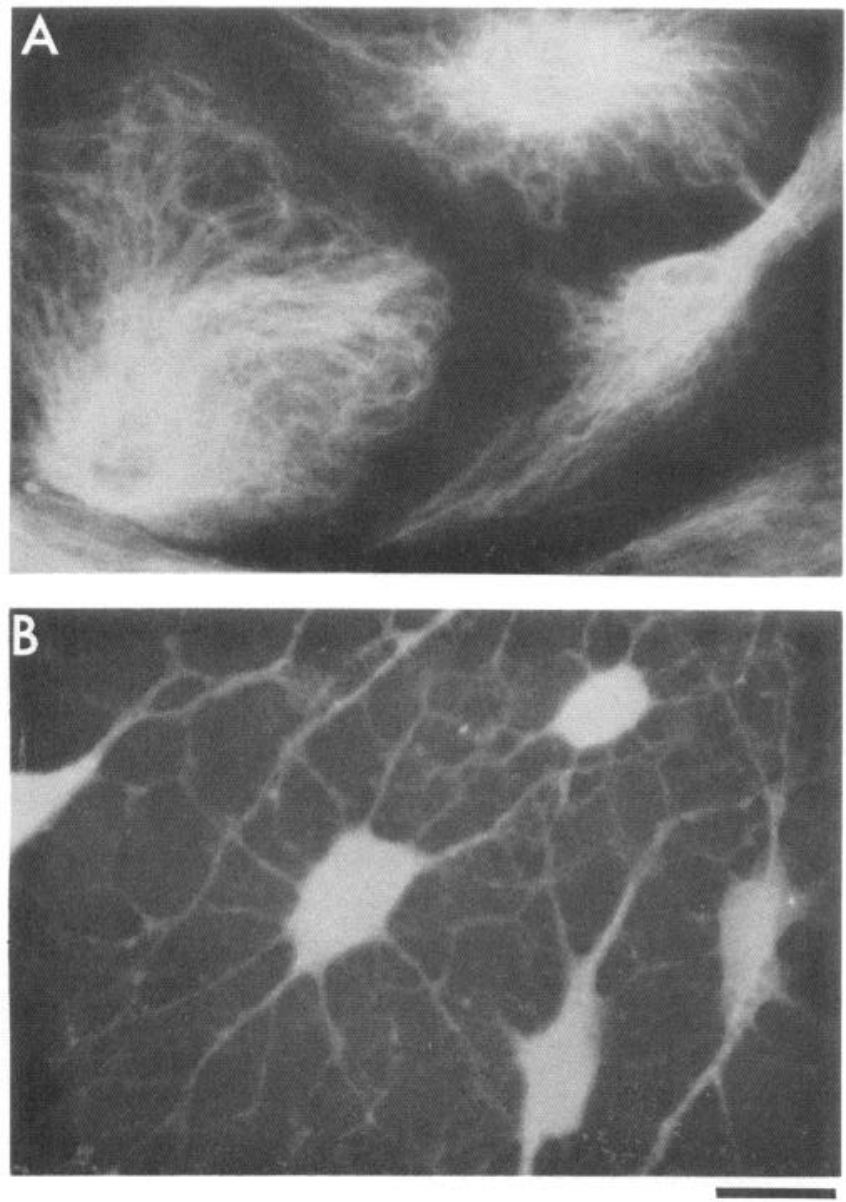

Figure 1. Cerebral cortical astrocytes in culture. A, Astrocytes from a control culture were labeled with a rabbit antiserum to GFAP followed by a rhodamine-conjugated antirabbit Ig antibody. Cells are flat with polygonal morphology. $B$, Astrocytes were incubated in forskolin for 1 $\mathrm{hr}$ and labeled with anti-GFAP as above. The morphological transformation included rounding up of the cell body, cytoplasmic retraction, and formation of multipolar processes. Scale bar, $20 \mu \mathrm{m}$.

responses recorded with a PDP 11/73 computer (INDEC). Analog signals were filtered with an 8-pole, low-pass Bessel filter before being digitized and recorded by the computer. In each experiment, linear capacitative and leakage currents were measured and subtracted before storage of data. The BCLAMP program set was used for acquisition and analysis of whole-cell data.

Solutions. Solutions for electrophysiological recording were designed to reveal even a small calcium current. The bath contained (in mм) 10 $\mathrm{Ca}^{2+}, 130 \mathrm{Cs}^{+}, 140$ methanesulfonate $-, 20 \mathrm{Cl}^{-}, 5 \mathrm{HEPES}$, and $10 \mu \mathrm{M}$ tetrodotoxin. In some experiments, the calcium was replaced with barium, which is more permeant than calcium through most calcium channels and hence produced larger currents. The pipette solution, which replaces soluble cytoplasmic constituents, contained $140 \mathrm{Cs}^{+}, 140$ methanesulfonate ${ }^{-}, 1 \mathrm{Mg}^{2+}, 2 \mathrm{Cl}^{-}, 0 \mathrm{Ca}^{2+}$ buffered to $10^{-9} \mathrm{M}^{2}$ free $\mathrm{Ca}^{2+}$ with 10 EGTA, and 5 HEPES. Both solutions were titrated to $\mathrm{pH} 7.4$. These solutions produced less than a $2 \mathrm{mV}$ junction potential. Therefore, correction of data for a junction potential offset was not necessary.

\section{Results}

\section{Cells in control cultures do not express calcium channels}

The typical morphological appearance of cultured cortical astrocytes is illustrated in Figure $1 A$. We recorded whole-cell currents from 30 astrocytes in these cultures. Voltage-sensitive calcium current was not detected in any cell from control cultures, even with the elevated $(10 \mathrm{~mm})$ calcium concentration of the

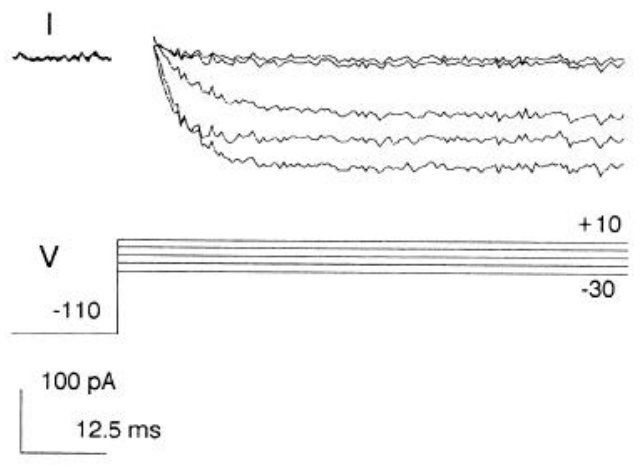

Figure 2. Induction of a voltage-sensitive calcium current by forskolin. Whole-cell calcium current recorded from a cortical astrocyte after a 1-hr incubation with forskolin $(10 \mu \mathrm{M})$. Currents were evoked by a series of test depolarization steps, from a holding potential of $-110 \mathrm{mV}$ to voltages ranging from -45 to $+60 \mathrm{mV}$. In this example, responses to test steps of $-30,-20,-10,0$, and $10 \mathrm{mV}$ are shown. The current began to activate at depolarizations above $-30 \mathrm{mV}$. It inactivated slowly over several hundred milliseconds.

bath solution. We would have detected any current greater than $10 \mathrm{pA}$.

\section{Calcium currents are induced by forskolin}

The absence of detectable calcium currents in cortical astrocytes was unexpected, since MacVicar (1984) had reported previously that astrocytes in culture fire slow calcium action potentials. In his experiments, membrane potential was measured with a microelectrode after the cells had been rounded up by preincubation in dibutyryl cAMP to facilitate impalement. Therefore, we reproduced more closely the conditions of those experiments. The cells were incubated for $1-2 \mathrm{hr}$ in substances known to increase or mimic cAMP in astrocytes: forskolin $(10 \mu \mathrm{M})$ or 8-bromo-cAMP (1 mM) (Wu and deVellis, 1983). These agents caused the same morphological changes reported for dibutyryl cAMP (Lim et al., 1973; Trimmer et al., 1982): the cell body became rounded, and multipolar processes were formed secondary to cytoplasmic retraction. Unlike dibutyryl cAMP, which took at least $2-3 \mathrm{hr}$ to induce these changes, forskolin and 8-bromo-cAMP acted more quickly. Forskolin produced a maximum morphological change within $1 \mathrm{hr}$ (Fig. $1 B$ ), but changes could be seen beginning within minutes.

After incubation, the coverslip containing the cells was rinsed and transferred to the recording chamber. The bath and pipette solutions did not contain forskolin or 8-bromo-cAMP. Under these conditions, cells displayed a voltage-sensitive calcium current ranging from -50 to $-200 \mathrm{pA}$ in peak inward current (Fig. 2). A voltage-dependent calcium current was observed in $100 \%$ of cells after forskolin incubation. The current was activated by depolarizations to $-30 \mathrm{mV}$ or more and had only a slow, voltage-independent inactivation occurring over hundreds of milliseconds. As is typical of many voltage-dependent calcium currents, it was blocked completely by certain inorganic cations (Fig. 3), including cobalt (5 mM) and cadmium (100 $\mu \mathrm{M})$. Because the inactivation process was slow relative to activation, the calcium currents elicited by ramp voltage commands closely approximated the peak current-voltage [I(V)] relationship and are demonstrated in the figures. Calcium currents (and rounding of cells) were induced when cells were incubated in forskolin concentrations as low as $100 \mathrm{~nm}$. 


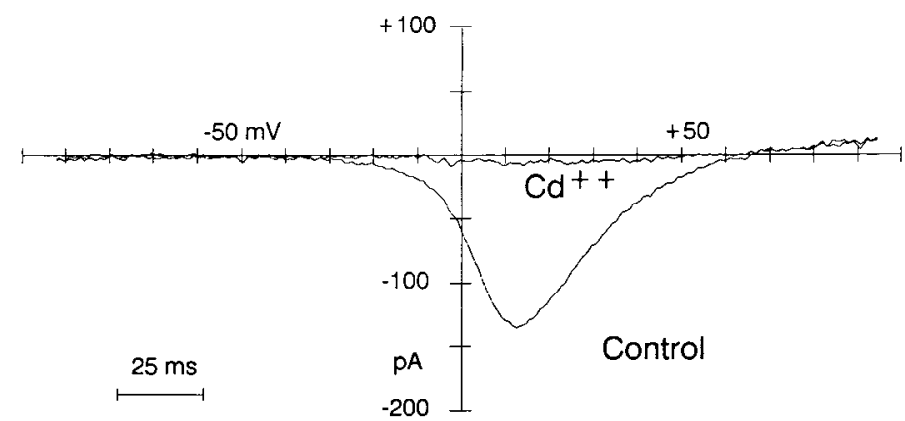

Figure 3. Blockade of voltage-sensitive calcium current by cadmium. Whole-cell calcium current was elicited with a ramp voltage command that changed from -100 to $+100 \mathrm{mV}$ over $250 \mathrm{msec}$. Linear leakage current was subtracted from the current response. Cadmium $(100 \mu \mathrm{M})$ completely abolished the current.

The time course of appearance of current was closely correlated with the time course of morphological change, although the earliest we studied current was $15 \mathrm{~min}$ after incubation. That is, before cells rounded up, calcium currents were absent or small; larger currents were observed only with maximal morphological changes. Thus, large calcium currents coincident with morphological changes were induced earlier after onset of forskolin incubations (about $30 \mathrm{~min}$, with smaller currents present at about $15 \mathrm{~min}$ ) than with 8-bromo-cAMP (about one $\mathrm{hr}$ ) or with dibutyryl cAMP (about $2 \mathrm{hr}$ ).

\section{The induced current is an L-current}

This induced conductance thus appears similar to the " $L$," or longlasting, calcium channel described in dorsal root ganglion neurons (Nowycky et al., 1985). Like other calcium currents of this type, inward current progressively diminished or "washedout" over minutes during whole-cell recording (Fig. 4). In the cell of Figure 4, peak inward current was $-200 \mathrm{pA}$ immediately after establishment of the whole-cell configuration but had declined to less than $-100 \mathrm{pA} 20 \mathrm{~min}$ later. This figure also demonstrates that during recording, the $\mathrm{I}(\mathrm{V})$ relationship shifted progressively in the hyperpolarizing direction, typically by 20 to $30 \mathrm{mV}$. This phenomenon has been observed previously during whole-cell recording in other cell types, particularly for calcium currents (Marty and Neher, 1983; Corey et al., 1984). As with other L-type calcium channels, barium was also permeant, and when barium was the current carrier, currents exhibited little inactivation (data not shown).

In addition, in 3 of 3 cells the voltage-dependent calcium current was blocked by nifedipine $(100 \mu \mathrm{M})$, a dihydropyridine calcium antagonist that blocks L-current in other cells (Fig. 5). Other concentrations were not studied, nor were the effects of depolarizing prepulses on nifedipine interactions with the channel. In experiments with cells cultured in certain sera (see below), some cells exhibited another type of calcium current, a "T," or transient, current with a rapid voltage-dependent inactivation (see below). The nifedipine block was mostly specific for the $\mathrm{L}$ channel and not for the T component of current (Fig. 5). Control recordings using solutions containing ethanol $(0.5 \%)$, used to dissolve the nifedipine, did not block either current. We also observed that diazepam, a benzodiazepine agonist reported to displace nitrendipine binding in cortical astrocytes (Bender and Hertz, 1985) had no effects on calcium currents in concentrations as high as $100 \mu \mathrm{M}$ ( 3 of 3 cells; studied in the absence of nifedipine).

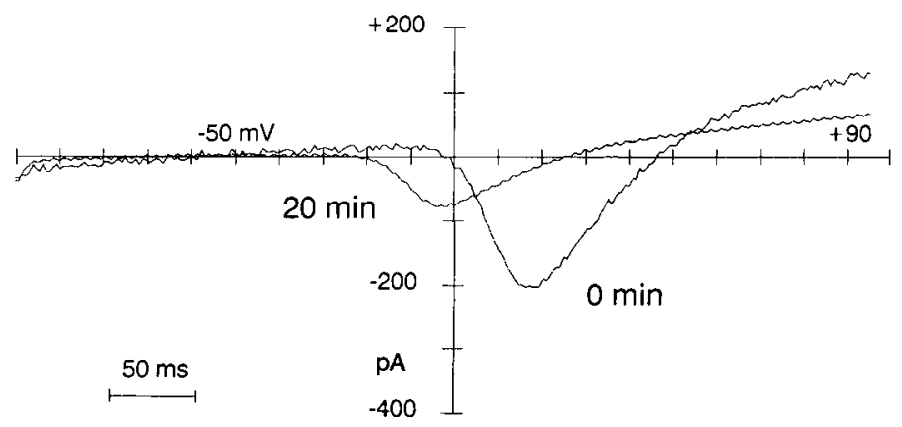

Figure 4. Wash-out of calcium current and shift of the activation potential. Whole-cell calcium currents were elicited by a ramp voltage command from -100 to $+100 \mathrm{mV}$ over $500 \mathrm{msec}$. Linear leakage currents were not subtracted. The current responses were obtained immediately after establishing the whole-cell configuration and after 20 min of recording. Over time, the peak current declined progressively, and the $I(V)$ relationship shifted in a hyperpolarizing direction.

\section{Calcium current in astrocytes is induced by neurotransmitters}

Can calcium currents in astrocytes be induced by a physiological substance? Astrocytes in culture express many neurotransmitter and peptide receptors, several of which have been shown to mediate an increase in intracellular cAMP. Among them are $\beta$-adrenergic receptors, and $\beta$-adrenergic agonists have been found to increase cAMP levels in astrocytes and to induce the morphological changes (McCarthy and deVellis, 1978; McCarthy and deVellis, 1983; Narumi et al., 1978). Therefore, we tested the ability of isoproterenol to induce a calcium current.

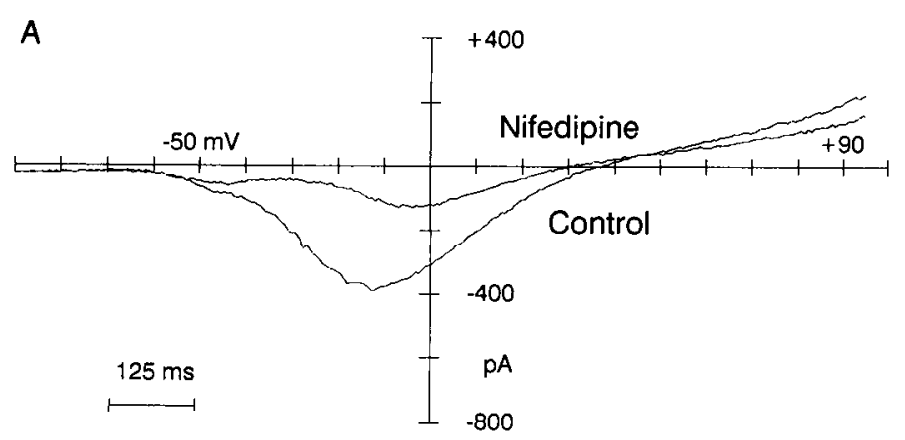

B

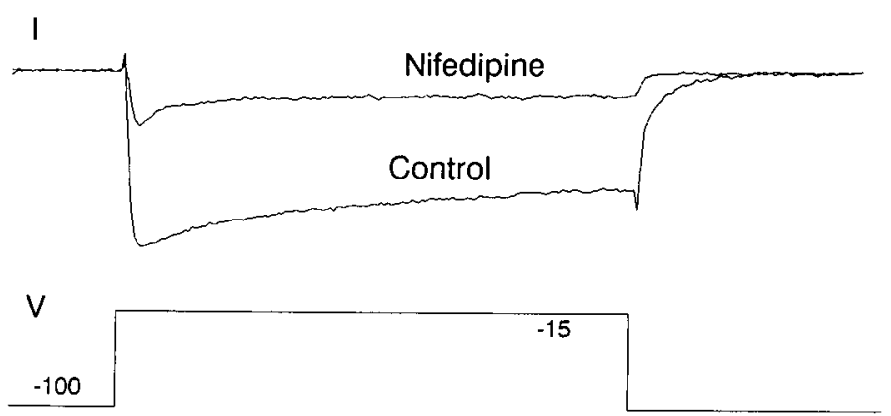

Figure 5. Nifedipine block of calcium current. Whole-cell current was elicited by a ramp voltage command $(A)$ and by a voltage step to -15 $\mathrm{mV}(B)$ and is shown in the same cell before and after nifedipine $(100$ $\mu \mathrm{M})$. The L-type current was decreased significantly. This cell also contained a small component of the T-type calcium current, which was blocked less strongly by the nifedipine. 


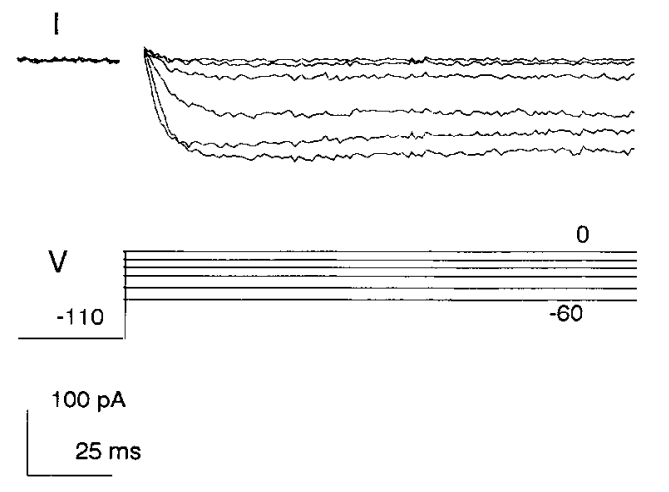

Figure 6. Induction of voltage-sensitive calcium current with isoproterenol. Preincubation of cultures in isoproterenol $(100 \mu \mathrm{M})$ for $30 \mathrm{~min}$ induced a whole-cell current indistinguishable from that induced by forskolin. Currents elicited from a prepulse of $-110 \mathrm{mV}$ to a series of voltage steps of $-60,-45,-30,-20,-10$, and $0 \mathrm{mV}$ are shown.

Cells were incubated with isoproterenol $(100 \mu \mathrm{M})$ and recorded from at intervals of $15 \mathrm{~min}$. Voltage-dependent calcium currents were induced, again with a time course that corresponded with morphological rounding changes (Fig. 6). Peak currents after 30 minutes of incubation in isoproterenol ranged from -50 to $-400 \mathrm{pA}$ (barium as current carrier; 20 of 20 cells). Prior to 30 min, little rounding of the cells or calcium current was observed. Isoproterenol could induce the current in concentrations as low as $1 \mu \mathrm{M}$. Below this concentration, we observed neither rounding of the cells nor expression of the calcium current.

VIP also has been reported to increase cAMP levels in cortical astrocytes in culture (Rougon et al., 1983). We next incubated cultured cortical astrocytes in VIP as described above. Because these incubations were performed in medium containing serum, we included aprotinin $(0.1 \mathrm{mg} / \mathrm{ml})$ during the incubation to prevent potential digestion of VIP by proteases present in the serum. Control experiments demonstrated that aprotinin did

Table 1. Effect of serum on expression of calcium currents

Fetal calf serum lot

\begin{tabular}{lll} 
(lot no.) & T current $^{a}$ & L current $^{b}$ \\
\hline M.A. Bioproducts (1) & - & - \\
M.A. Bioproducts (2) & - & - \\
M.A. Bioproducts (3) & - & + \\
Hyclone (1) & - & - \\
Hyclone (2) & - & - \\
Hyclone (3) & + & - \\
Hyclone (4) & - & + \\
Hyclone (5) & - & - \\
Hyclone (6) & - & - \\
Flow Labs (1) & + & - \\
Flow Labs (2) & - & - \\
Irvine Scientific & + & - \\
Hazelton (1) & - & - \\
Hazelton (2) & + & - \\
Gibco (1) & + & + \\
Gibco (2) & - & - \\
Gibco (3) & - & - \\
\hline
\end{tabular}

a Constitutive.

${ }^{b}$ Inducible.

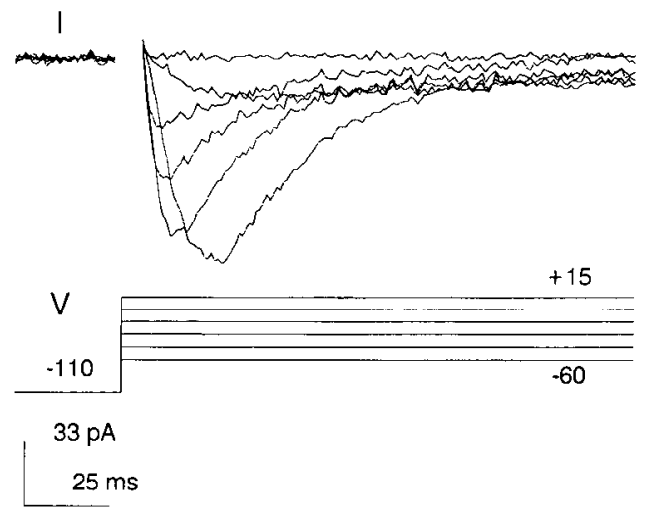

Figure 7. A T-type calcium current observed after culture in certain lots of serum. Whole-cell current was elicited by voltage steps from a holding potential of $-110 \mathrm{mV}$ to $-60,-45,-30,-15,0$, and +15 $\mathrm{mV}$. The current displayed a voltage-dependent inactivation that was more rapid for larger depolarizations. T-type calcium current was observed in these cultures both before and after treatment with forskolin.

not affect the induction of calcium currents by forskolin. At VIP concentrations of $100 \mathrm{nM}$, calcium currents ranging from -30 to $-300 \mathrm{pA}$ were induced in all astrocytes recorded from 30 min or greater ( 15 of 15 cells) and again correlated with the presence of morphological rounding. Currents were induced at incubation concentrations of $10 \mathrm{~nm}$, but no current could be induced with a concentration of $1 \mathrm{nM}$, even with longer incubations extending to $2 \mathrm{hr}$.

Although these experiments suggest that isoproterenol and VIP may induce calcium current by increasing intracellular cAMP, they do not prove it. To gain further support for this hypothesis, we studied the effect of simultaneous incubation in subthreshold concentrations of both isoproterenol $(100 \mathrm{nM})$ and forskolin $(10 \mathrm{nM})$ to look for synergy. Neither of these concentrations alone induced calcium current or morphological changes in the astrocytes. However, after $30 \mathrm{~min}$ of simultaneous incubation, we observed a mild rounding and process formation in cells and small calcium currents averaging about $35 \mathrm{pA}$ with barium as current carrier ( 4 of 5 cells).

\section{Effect of serum on calcium current expression and induction}

Although in our initial experiments incubation in forskolin reliably induced I -type calcium currents, in subsequent experiments we observed that forskolin induction of calcium current was highly dependent on the batch of fetal calf serum used to culture the astrocytes (Table 1). Most of our initial experiments were done on astrocytes cultured in serum from M.A. Bioproducts (lot 3). When this lot expired, we used a new lot of serum from the same manufacturer and found that forskolin no longer induced calcium currents in the astrocytes. We tested a total of 17 different lots of fetal calf serum and found that calcium current expression depended on the serum in two ways.

First, some lots of sera were permissive for induction of L-type calcium currents ( 3 of 17 lots). In these lots, calcium currents could be induced by forskolin incubation but were never present in control cultures. In the other 14 lots, calcium currents were never induced, although forskolin did promote the usual rounding of the cells. L-type calcium currents were never present in control cultures prepared with any lot of serum.

We wondered whether this permissive effect could be exerted acutely. When cells cultured in a nonpermissive lot of serum 
were incubated in forskolin for $30-60 \mathrm{~min}$ in a new medium containing only permissive serum, calcium currents could not be induced (12 of 12 cells). However, if cells were cultured initially in nonpermissive serum and then cultured at least 48 $\mathrm{hr}$ in a permissive serum, forskolin could induce L-type calcium currents ( 7 of 7 cells).

Second, some lots of serum (5 of 17) allowed the constitutive expression of another type of calcium channel, the " $T$," or transient, type channel described by Nowycky et al. (1985). As described in other cell types, this current had a rapid voltagedependent inactivation and activated at about $-60 \mathrm{mV}$ (Fig. 7). Peak inward current was diminished with depolarizing prepulses (not shown). Its properties were not further characterized. With these lots of sera, the T-type calcium current was present before incubation in forskolin. We did not study possible effects of forskolin on the T-type current.

\section{Cell type specificity of calcium current expression}

Type 1 astrocytes in the optic nerve are similar to cortical astrocytes in some respects, including morphology in culture, response to growth factors, and antigenic phenotype (Raff et al., 1983a; Raff and Miller, 1984). Like cortical astrocytes, type 1 astrocytes did not normally express calcium channels in culture but were induced to express channels after incubation in forskolin. The response of type 1 astrocytes to forskolin was much less robust; only small currents of $50 \mathrm{pA}$ or less were induced. In these experiments and those described below involving other cell types, we exclusively studied cells that had been cultured in permissive lots of fetal calf serum.

Optic nerve oligodendrocytes in cultures prepared according to the procedures of Raff et al. (1983b) could not be induced to express a calcium current with incubation in forskolin. Type 2 astrocytes (Raff et al., 1983a, b; Miller and Raff, 1984) express large $\mathrm{T}$ and $\mathrm{L}$ currents before forskolin incubation (Barres et al., 1988).

We also prepared purified cultures of meningeal (pial) cells according to the procedures of Noble and Murray (1984). Like the cortical astrocytes, meningeal cells were flat before incubation in forskolin but could be induced to round up and form processes with forskolin incubation. These changes were so pronounced that it was difficult to distinguish a forskolin-treated meningeal culture from a similarly treated cortical astrocyte culture by morphology alone. Nevertheless, forskolin never induced expression of calcium currents in purified meningeal cells ( 20 of 20 cells).

\section{Discussion}

Our findings demonstrate that L-type calcium channels are induced in cultured cortical astrocytes by substances known to increase their intracellular cAMP: forskolin, isoproterenol, and VIP. Because 8-bromo-cAMP was sufficient to induce these channels, it is likely that the isoproterenol and VIP effects were mediated by their established ability to increase intracellular cAMP in cortical astrocytes. The induction of the L-type calcium current appeared specific to cortical astrocytes and a closely related astrocyte type in white matter but did not occur in meningeal cells or oligodendrocytes. The ability of forskolin to induce calcium current in astrocytes depended on the previous culture of the cells in a permissive lot of serum for at least 48 hr.

Using 2 microelectrode voltage clamping, Tse and MacVicar (1987; MacVicar and Tse, 1988) also observed the "enhance- ment" of calcium current in primary cultures of cortical astrocytes by isoproterenol. The term "induction" is probably preferable, since L-type calcium current is entirely absent before incubation.

The induction of calcium current in astrocytes by neurotransmitters, such as VIP, is different from direct neurotransmitter gating of ion channels. In the latter case, the binding of the neurotransmitter to its receptor activates the ion channel directly, whereas in the induction mechanism we have described here, the ion channels are activated by voltage, and the effect of the transmitter is to make the channels available for voltage activation. Although many neurotransmitters have been shown to depolarize or hyperpolarize astrocytes, conclusive evidence that neurotransmitters can directly activate glial ion channels is only now coming to light (for review, see Barres et al., 1990).

\section{Possible mechanism of calcium channel induction}

How is the current induced? The channels may already exist in the plasma membrane in a silent or nonfunctional state that is made functional by phosphorylation. This mechanism is thought to underlie the increase in calcium current seen in myoctes after exposure to isoproterenol (Bean et al., 1984). However, there are two clear differences between the induction in myocytes and astrocytes: in myocytes the current is augmented from a basal level induced in seconds and returns to basal levels within minutes after washout of the transmitter, whereas in astrocytes the calcium current was completely absent before induction and remained for a long time after washout of the inducing substance (for at least $1 \mathrm{hr}$; data not shown). Another possibility, protein synthesis of new channels, is unlikely because the current appears within $15 \mathrm{~min}$. Dibutyryl cAMP induces a striking reorganization of the actin microfilament cytoskeleton in astrocytes (Opas et al., 1986), and it is possible that the cytoskeletal alteration itself induces function of calcium channels already present in the membrane, although it is not clear how that might happen. Finally, it may be that channels are recruited to the plasma membrane by insertion from an intracellular membrane compartment. This mechanism has been shown to explain insulin induction of glucose transporters to adipocyte membranes (Kono et al., 1982; Simpson and Cushman, 1985), hormonal recruitment of several ion transporters in epithelia (Schwartz and Al-Awqati, 1986; Wade, 1986), and possibly the recruitment of the apical sodium channel found in rabbit urinary bladder (Lewis and de Moura, 1984). As with the calcium channel in astrocytes, the glucose transporter is largely absent from adipocyte plasma membranes, is induced within minutes after insulin exposure, and remains in the membrane for several hours (at room temperature) after the insulin is proteolyzed.

An intriguing question left unanswered by the present study is how the timecourse of the rise and fall of intracellular cAMP correlates with the induction of the calcium channel. First, are calcium channels recruited instantly with the rise in cAMP? The timecourse of forskolin induction of calcium current corresponds closely with that of forskolin-induced cAMP increase in cortical astrocytes (Wu and deVellis, 1983). This question possibly could be addressed in future experiments by inclusion of cAMP (or caged CAMP) in the patch pipette solution. Second, when cAMP falls back to basal levels after withdrawal of the inducer, do the calcium channcls pcrsist? Our data suggest that this may the case. Calcium channels are present for at least 1 $\mathrm{hr}$ after withdrawing forskolin, yet cAMP has been shown to return to basal levels within 10 min of forskolin withdrawal (Wu and deVellis, 1983). 


\section{Are calcium channels expressed by astrocytes in vivo?}

Walz and MacVicar (1988) recorded from astrocytes in hippocampal slices and failed to induce slow action potentials using a bath solution similar to that which allowed them to observe action potentials in cultures. However, they did nol incubate the tissue in dibutyryl cAMP, and the cells were not definitively identified as astrocytes by labeling with GFAP antibodies. Thus, these experiments do not rule out the possibility that calcium currents may be induced in astrocytes in vivo.

It may be possible to determine whether astrocytes express calcium channels in vivo by recording from acutely dissociated cells. Although we have not been able to induce L-type calcium currents in acutely dissociated type 1 astrocytes from optic nerve (unpublished observations), lack of a definitive surface marker has made it difficult to study acutely isolated cortical astrocytes. Thus, it remains unclear whether induction occurs in vivo. Similarly, it remains to be determined whether astrocytes in vivo express $\beta$-adrenergic or VIP receptors.

\section{Potential functional significance of an astrocyte calcium channel}

If present in vivo, what role could this calcium channel play in normal astrocytic function? Calcium entry could activate particular calcium-dependent enzymes, such as those involved in the glycogenolytic pathway (Ververken et al., 1982) or regulate the permeability of gap junctions that are known to couple glia extensively. It could play a role in activating calcium-dependent channels, such as the calcium-activated potassium channel present in cortical astrocytes in culture (Quandt and MacVicar, 1986). Calcium entry could be involved in the mediation of a secretory process. Taurine release by astrocytes in culture has been shown to be triggered by $\beta$-adrenergic agonists (Shain et al., 1986). Finally, the channel might affect neuronal excitability by decreasing calcium in the extracellular space.

A recurrent issue in studies of voltage-dependent ion channels in nonexcitable cell types is whether the cell is ever depolarized sufficiently in vivo to allow activation of the ion channel. This is certainly a concern for L-type calcium channels, which activate at $-30 \mathrm{mV}$. The T-type calcium current, on the other hand, can be activated with only very slight depolarizations, about $-60 \mathrm{mV}$ under the conditions of our recording, and perhaps even closer to $-70 \mathrm{mV}$ with physiological calcium concentrations (that screen surface charge to a lesser extent). Moreover, because of the strong voltage dependence of the T-type calcium current decay, shallow depolarizations evoked relatively sustained currents (Fig. 7).

MacVicar (1987) suggested that the morphological transformation induced by cAMP is mediated by the induced calcium entry. In support, he showed that the morphological transformation could be blocked by concentrations of cadmium or cobalt that blocked the calcium currents. However, this hypothesis appears untenable for at least three reasons. First, $\beta$-adrenergic agonists have been reported to hyperpolarize astrocytes in culture (Hosli et al., 1982), and this would not allow activation of either T- or L-type voltage-dependent calcium channels. Second, we have found with nonpermissive sera that the morphological transformation occurs in the absence of voltage-dependent calcium current. Third, a similar morphological transformation occurs in meningeal cells, yet these cells are not induced to express calcium currents.

\section{Serum effects on calcium channel expression}

Serum affected calcium channel expression in astrocytes in two distinct ways. Culture of astrocytes in some lots of sera induced the constitutive expression of a T-type calcium channel. Other lots of sera were permissive for the induction of the L-type channel by forskolin. Most did neither. There appeared to be no correlation between these two effects. Each could exist in isolation, or they could be found together. Because the permissive effect could not be exerted acutely but required culture in the permissive serum for at least $48 \mathrm{hr}$, it is likely that the permissive lots of sera induce the synthesis and expression of a protein. Such a protein could be the calcium channel itself, a regulatory protein, or another protein involved in the induction process. These findings serve to reinforce the need for correlation of in vitro electrophysiological properties with actual in vivo behavior.

\section{References}

Ballanyi, K., P. Grafe, and G. ten Bruggencate (1987) Ion activities and potassium uptake mechanisms of glial cells in guinea-pig olfactory cortex slices. J. Physiol. (Lond.) 382: 159-174.

Barres, B. A., L. L. Y. Chun, and D. P. Corey (1988) Ion channel expression by white matter glia: I. Type 2 astrocytes and oligodenrocytes. Glia 1: 10-30.

Barres, B. A., L. L. Y. Chun, and D. P. Corey (1990) Ion channels in vertebrate glia. Annu. Rev. Neurosci. 13: in press.

Bcan, B. P., M. C. Nowycky, and R. W. Tsien (1984) $\beta$-adrenergic modulation of calcium channels in frog ventricular heart cells. Nature 307: 371-375.

Bender, A. S., and L. Hertz (1985) Pharmacological evidence that the non-neuronal diazepam binding site in primary cultures of glial cells is associated with a calcium channel. Eur. J. Pharmacol. 110: 287288 .

Bevan, S., S. Y. Chiu, P. T. A. Gray, and J. M. Ritchie (1985) The presence of voltage-gated sodium, potassium and chloride channels in rat cultured astrocytes. Proc. R. Soc. Lond. [Biol.] 225: 299-313.

Chun, L. L. Y., B. A. Barres, and D. P. Corey (1986) Induction of a calcium channel in astrocytes by cAMP. Soc. Neurosci. Abstr. 12: 368.4 .

Coles, J. A., and R. K. Orkand (1983) Modification of potassium movement through the retina of the drone (Apis mellifera) by glial uptake. J. Physiol. (Lond.) 340: 157-174.

Corey, D. P., and C. F. Stevens (1983) Science and technology of patch-recording electrodes. In Single-Channel Recording, B. Sakmann and E. Neher, eds., pp. 53-68, Plenum, New York.

Corey, D. P., J. M. Dubinsky, and E. A. Schwarz (1984) The calcium current in inner segments of rods from the salamander. (Ambystoma tigrinum) retina. J. Physiol. (Lond.) 354: 557-575.

Eisenbarth, G. S., F. S. Walsh, and M. Nirenberg (1979) Monoclonal antibody to a plasma membrane antigen of neurons. Proc. Natl. Acad. Sci. USA 76: 4913-4917.

Hamill, O. P., A. Marty, E. Neher, B. Sakmann, and F. J. Sigworth (1981) Improved patch-clamp techniques for high-resolution current recording from cells and cell-free membrane patches. Pfluegers Arch. 391: $85-100$.

Hosli, L., E. Hosli, C. Zehntner, R. Lehman, and T. W. Lutz (1982) Evidence for the existence of alpha- and beta-adrenoceptors on cultured glial cells - an electrophysiological study. Neuroscience $7: 2867-$ 2872.

Huettner, J. E., and R. W. Baughman (1986) Primary culture of identified neurons from the visual cortex of postictal rats. J. Neurosci. 6 : 3044-3060.

Kono, T., F. W. Robinson, T. L. Blevins, and O. Ezaki (1982) Evidence that translocation of the glucose transport activity is the major mechanism of insulin action on glucose transport in fat cells. J. Biol. Chem. 257: 10942-10947.

Lewis, S. A., and J. L. C. de Moura (1984) Apical membrane area of rabbit urinary bladder increases by fusion of intracellular vesicles: An electrophysiologic study. J. Membr. Biol. 82: 123-136.

Lim, R., K. Mitsunobu, and W. K. P. Li (1973) Maturation-stimu- 
lating effect of brain extract and dibutyryl cyclic AMP on dissociated embryonic cells in culture. Exp. Cell. Res. 79: 243-246.

MacVicar, B. A. (1984) Voltage-dependent calcium channels in glial cells. Science 226: 1345-1347.

MacVicar, B. A. (1987) Morphological differentiation of cultured astrocytes is blocked by cadmium or cobalt. Brain Res. 420: 175-177.

MacVicar, B. A., and F. W. Tse (1988) Norepinephrine and cAMP enhance a nifedipine-sensitive calcium current in cultured rat astrocytes. Glia $1: 359-365$.

Marty, A., and E. Neher (1983) Tight-seal whole-cell recording. In Single-Channel Recording, B. Sakmann and E. Neher, eds., pp. 107122, Plenum, New York.

McCarthy, K. D. (1983) An autoradiographic analysis of beta-adrenergic receptors on immunohistochemically defined astroglia. J. Pharm. Exp. Ther. 226: 282-290.

McCarthy, K. D., and J. deVellis (1978) Alpha-adrenergic receptor modulation of beta-adrenergic, adenosine and prostaglandin $\mathrm{E} 1$ increased 3:5-cyclic monophosphate levels in primary cultures of glia. J. Cyclic Nucleotide Res. 4: 15-26.

McCarthy, K. D., and J. deVellis (1980) Preparation of separate astrogial and oligodendroglial cell cultures from rat cerebral tissue. J. Cell. Biol. 85: 890-902.

Miller, R. H., and M. C. Raff (1984) Fibrous and protoplasmic astrocytes are biochemically and developmentally distinct. J. Neurosci. 4: 585-592.

Miller, R. H., S. David, R. Patel, E. K. Abney, and M. C. Kaff (1985) A quantitative immunohistochemical study of macroglial cell development in the rat optic nerve: in vivo evidence for two distinct astrocyte lineages. Dev. Biol. 111: 35-41.

Narumi, S., H. K. Kimelberg, and R. S. Bourke (1978) Effects of norepinephrine on the morphology and some enzyme activities of primary monolayer cultures from rat brain. J. Neurochem. 31: 14791490.

Noble, M., and K. Murray (1984) Purified astrocytes promote the in vitro division of a bipotential glial progenitor cell. EMBO J. 3: 22432247.

Nowycky, M. C., A. P. Fox, and R. W. Tsien (1985) Three types of neuronal calcium channel with different calcium agonist sensitivity. Nature 316: 440-443.

Opas, M., V. I. Kalnins, and S. Fedoroff (1986) Spectrin does not redistribute with actin during $\mathrm{dBcAMP}$-induced changes in astrocytes in vitro. Dev. Br. Res. 25: 314-317.

Quandt, F. N., and B. A. MacVicar (1986) Calcium activated potassium channels in cultured astrocytes. Neuroscience 19:29-41.

Raff, M. C., and R. H. Miller (1984) Glial cell development in the rat optic nerve. TINS $7: 469-472$.
Raff, M. C., R. H. Miller, and M. Noble (1983a) A glial progenitor cell that develops in vitro into an astrocyte or an oligodendrocyte depending on culture medium. Nature 303: 390-396.

Raff, M. C., E. R. Abney, J. Cohen, R. Lindsay, and M. Noble (1983b) Two types of astrocytes in cultures of developing rat white matter: Differences in morphology, surface gangliosides, and growth characteristics. J. Neurosci. 3: 1289-1300.

Raff, M. C., E. R. Abney, and R. H. Miller (1984) Two glial cell lineages diverge prenatally in rat optic nerve. Dev. Biol. 106: 53-60.

Ranscht, B., P. A. Clapshaw, J. Price, M. Noble, and W. Seifert (1982) Development of oligodendrocytes and Schwann cells studied with a monoclonal antibody against galactocerebroside. Proc. Natl. Acad. Sci. USA 79: 2709-2713.

Rougon, G., M. Noble, and A. W. Mudge (1983) Neuropeptides modulate the $\beta$-adrenergic response of purifed astrocytes in vitro. Nature 305: 715-717.

Schwartz, G. J., and Q. Al-Awqati (1986) Regulation of transepithelial $\mathrm{H}+$ transport by exocytosis and endocytosis. Annu. Rev. Physiol. 48. 153-161.

Shain, W., V. Madclian, D. L. Martin, H. K. Kimclbcrg, M. Pcrronc, and R. Lepore (1986) Activation of beta-adrenergic receptors stimulates release of an inhibitory transmitter from astrocytes. J. Neurochem. 46: 1298-1303.

Simpson, I. A., and S. W. Cushman (1985) Regulation of glucose transporter and hormone receptor cycling by insulin in the rat adipose cell. Curr. Top. Memb. Trans. 24: 459-503.

Trimmer, P. A., P. J. Reier, T. H. Oh, and L. F. Eng (1982) An ultrastructural and immunocytochemical study of astrocytic differentiation in vitro. J. Neuroimmunol. 2: 235-260.

Tse, F. W., and B. A. MacVicar (1987) Isoproterenol enhances calcium current in cultured astrocytes. Soc. Neurosci. Abstr. 13: 330.12.

Ververken, D., P. V. Van Veldhoven, C. Proost, H. Carton, and H. DeWulf (1982) On the role of calcium ions in the regulation of glycogenolysis in mousc brain cortical sliccs. J. Ncurochem. 38: 12861295.

Wade, J. B. (1986) Role of membrane fusion in hormonal regulation of epthelial transport. Annu. Rev. Physiol. 48: 213-223.

Walz, W., and B. MacVicar (1988) Electrophysiological properties of glial cells: Comparison of brain slices with primary cultures. Brain Res. 443: 321-324.

Wu, D. K., and J. deVellis (1983) Effect of forskolin on primary cultures of astrocytes and oligodendrocytes. J. Cyclic Nucleotide Res. 9: 59-67. 